\title{
Influence of age and renal disease on aminoglycoside dosage
}

\author{
Th. Hallynck ${ }^{\star}$, H. H. Soep $\dagger$ and L. Dettli $\dagger$
}

Department of Microbiology, Faculty of Pharmacy, University of Gent, Apotheekstraat 1 , B9000 Gent, Belgium* Department of Clinical Research, Bristol Myers International Corporation, Brussels, Belgium, $\dagger$ and Department of Internal Medicine, University of Basel, Switzerland. $\uparrow$

\begin{abstract}
New guidelines for the administration of amikacin are presented for neonates, children and adults, with normal or impaired, stable or changing renal function. The dose is calculated according to the lean body mass, which can be estimated from weight, height and sex of the patient. The dosing interval is calculated from the predicted drug half-life, which is derived from creatinine clearance normalized to $50 \mathrm{~kg}$ lean body mass (LBM). A formula is presented to estimate directly the $C_{\mathrm{cr}}$ in $\mathrm{ml} / \mathrm{min}$ per $50 \mathrm{~kg} \mathrm{LBM}$, based only upon serum creatinine concentrations and the age of the subject. Two electronic pocket calculators which contain the dosage guidelines of a mikacin are also described.
\end{abstract}

Les auteurs présentent de nouvelles recommandations pour la détermination de la posologie de l'amikacine chez les nouveau-nés, les enfants et les adultes dans le cas de fonction rénale normale ou altérée, de façon stable ou variable.

La dose est calculée selon la masse corporelle 'dégraissée' qui est évaluée en fonction du poids, de la taille et du sexe du malade. L'intervalle entre les doses est calculé à partir de la demi-vie estimée selon la valeur de la clairance de la créatinine rapportée à $50 \mathrm{~kg}$ de masse corporelle 'dégraissée'.

Une formule est donnée, qui permet de calculer directement la clairance de la créatinine en $\mathrm{ml} / \mathrm{min} / 50 \mathrm{~kg}$ de masse corporelle dégraissée bascé uniquement sur la créatininémie et l'âge du sujet.

Deux calculateurs de poche programmes pour le calcul de la posologie de l'amikacine sont décrites.

\section{Introduction}

All drug dosage rules are originally based upon the drug half-life. However, the direct measurement of the drug half-life is not always possible, because serum assays are not always available for each drug. Even if the serum drug levels can be obtained, corrections can only be done after the dosage regimen has been applied. 
No information on the dosage regimen can be given before the first dose. Furthermore, quality-control surveys on aminoglycosides have shown that only a few laboratories appear to be capable of producing accurate results (Reeves \& Bywater, 1975). Even in specialized laboratories errors of more than $100 \%$ often occur (Pijck \& Hallynck, 1981). It is, therefore, not surprising that dosage guidelines are notdirectly based upon drug half-life, but on serum creatinine concentrations $\left(S_{\mathrm{cr}}\right)$, or on creatinine clearance $\left(C_{\mathrm{er}}\right)$ determinations or estimations.

With all dosage guidelines, it is essential that similar drug half-lives should be obtained, when $S_{\mathrm{cr}}$ or $C_{\mathrm{cr}}$ are the same in two individuals. Only with $C_{\mathrm{cr}}$, normalized to $50 \mathrm{~kg}$ lean body mass (LBM), do similar half-lives of amikacin, gentamicin and tobramycin occur with identical $C_{\mathrm{cr}}$, independently of the age of the patient.

Gentamicin half-lives, estimated from $C_{\text {cr }}$ expressed in $\mathrm{ml} / \mathrm{min}$ or in $\mathrm{ml} / \mathrm{min}$ per $1.73 \mathrm{~m}^{2}$ body surface area (BSA) can be quite different from the measured half-life, especially in neonates and children. Only with $C_{\mathrm{cr}}$, normalized to $50 \mathrm{~kg} \mathrm{LBM}$, can reliable estimations of gentamicin half-lives be obtained independent of the age of the subject (Hallynck et al., 1981)

\section{Materials and methods}

In five independent centres (Brugge, Belgium; Perugia, Italy; Prague, Czechoslovakia; Rouen, France; Tel Aviv, Israel), 62 patients were treated with amikacin. Four centres treated 48 patients by intravenous administration (iv) and one centre used the intramuscular route (i.m.) in 14 patients. Most of the patients (53) had serious Gram-negative infections of the urinary tract; 3 suffered from respiratory illness and 6 patients had sepsis. Of the patients, $19 \%$ were chronically infected. Seventeen patients had a $C_{\mathrm{cr}}$ below $30 \mathrm{ml} / \mathrm{min}$. The age of the patients ranged from 19-82 years. Each patient received a loading dose of 7.5 (iv) or 10 (i.m.) $\mathrm{mg} / \mathrm{kg}$ LBM. The individual LBM was calculated from skinfold measurements as reported previously (Hallynck et al., 1980).

\section{Determination of the individual LBM}

The method for the determination of the LBM, used in this multi-centre trial of amikacin in renal patients is too complex for routine use in clinical practice. Furthermore, the method is only valid in adults (Hallynck et al., 1980): another graph and another place on the body (triceps) are required for skinfold measurements in children. Because of the practicality and the good correlation with the skinfold technique, we suggest that the LBM in neonates, children and adults should be calculated from the following formula, which is based upon the work of James (1976): 
for males: $\quad \mathrm{LBM}=1 \cdot 10 W-128 \frac{W^{2}}{H^{2}}$

for females: $\mathrm{LBM}=1.07 W-148 \frac{W^{2}}{H^{2}}$

where LBM = lean body mass in $\mathrm{kg}, W=$ weight in $\mathrm{kg}, H=$ height in $\mathrm{cm}$.

As in the formula of Dubois \& Dubois (1916) for the estimation of the body surface area, the formula presented is based upon the weight and the height of the subject. This has one major disadvantage: any overweight of the subject will be converted by the formula into an excess of body fat, even if the overweight is due to an excess of muscle. However, even in athletes, an excess of muscle is usually accompanied by a large amount of body fat, so that for most individuals, the formula presented can still be used. Only in some individuals, for example professional football players, is an excess of musculature together with a decreased amount of body fat sometimes found (Behnke \& Willmore, 1975).

The dosage rules for amikacin were based upon the predicted drug half-life and normalized $C_{\mathrm{cr}}$, calculated from a daily $S_{\mathrm{cr}}$ determination and the age of the patient. In patients with normal renal function, amikacin was given in doses of $7 \cdot 5$ (i.v.) or 10 (i.m.) $\mathrm{mg} / \mathrm{kg}$ LBM every $12 \mathrm{~h}$. In patients with impaired renal function, the dose was reduced to three-quarters of the loading dose. The dosage interval was calculated as twice the individual drug half-life of amikacin and rounded up to the nearest usual dosage interval: $12,24,36,48,72 \mathrm{~h}$, or longer.

Each day, serum and complete $24 \mathrm{~h}$ urine collections were sampled and frozen at $-20^{\circ} \mathrm{C}$. Only after the study was finished, were all these samples analysed to measure the daily 24 -h endogenous $C_{\mathrm{cr}}$ and to construct three amikacin serum curves, each with five points, at the beginning, middle and end period of therapy. The aim of the proposed schedule was to obtain peak levels of $25 \pm 5 \mathrm{mg} / \mathrm{l}$ and trough levels below $5 \pm 2 \mathrm{mg} / \mathrm{l}$. It was also possible to compare afterwards, for the three periods mentioned, the drug half-life with the measured 24-h endogenous $C_{\mathrm{cr}}$ in $\mathrm{ml} / \mathrm{min}$ and with the $C_{\mathrm{cr}}$ in $\mathrm{ml} / \mathrm{min}$ per $50 \mathrm{~kg} \mathrm{LBM}$, which was estimated during the study and on which the dosage schedule was based during the 8 days of therapy.

\section{Prediction of the half-life of drugs}

The half-life of drugs, partly or mainly excreted by the kidneys, can be estimated for each individual (neonate, child or adult) from $C_{\mathrm{cr}}$, when $C_{\mathrm{cr}}$ is normalized to $50 \mathrm{~kg}$ LBM:

$$
T / 2=\frac{F_{\mathrm{r}}}{F_{\mathrm{nr}}+C_{\mathrm{cr}}}
$$

where $T /_{2}=$ half-life of the drug in hours, $F_{\mathrm{r}}=$ renal correlation factor of drug elimination and $C_{\mathrm{cr}}, F_{\mathrm{nr}}=$ non-renal correlation factor of drug elimination and $C_{\mathrm{cr}}$.

For amikacin: $F_{\mathrm{r}}=171, F_{\mathrm{nr}}=1$. A list of $F_{\mathrm{r}}$ and $F_{\mathrm{nr}}$ of more than 250 drugs is in preparation. 


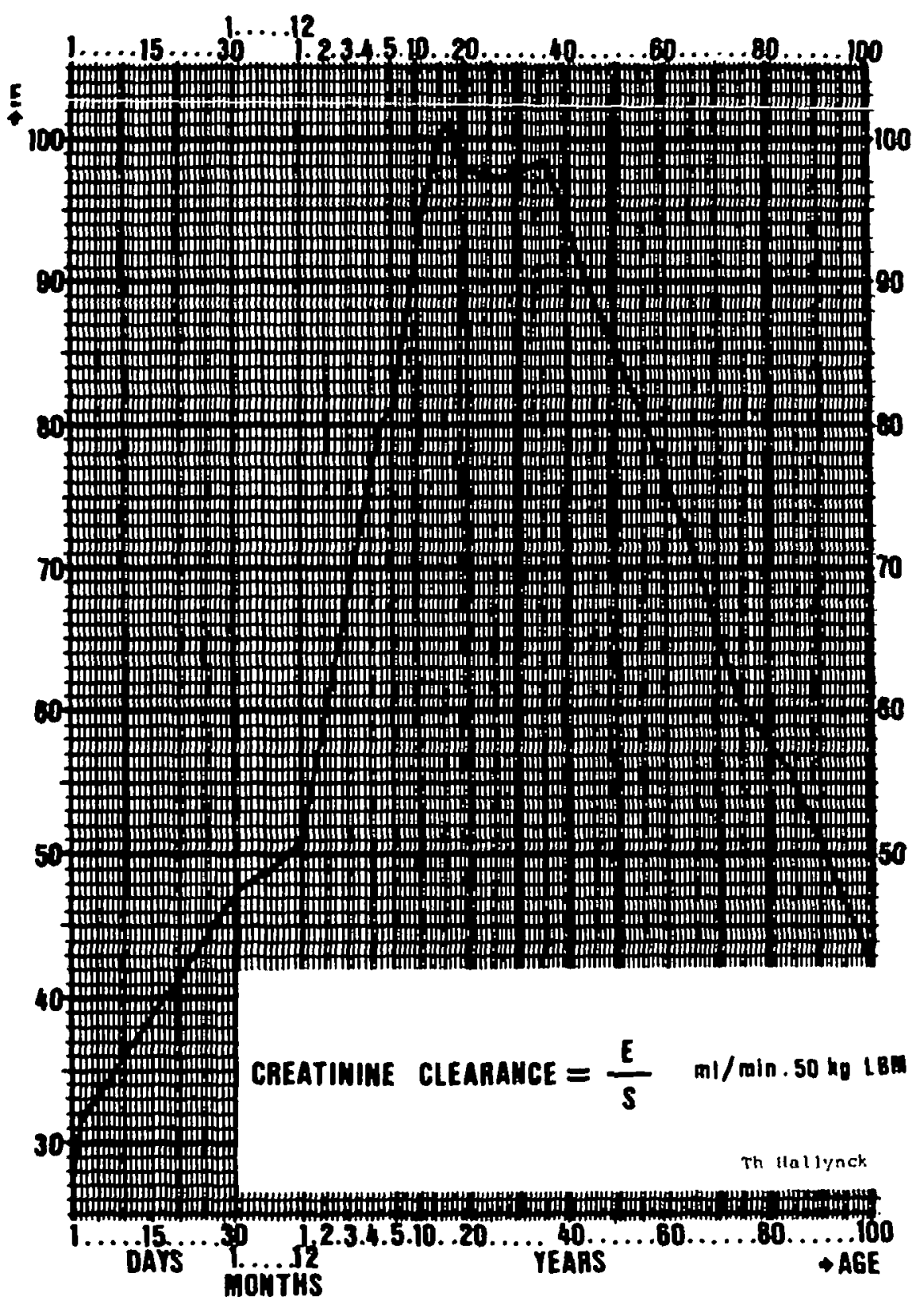

Figure 1. Determination of creatinine clearance in $\mathrm{ml} / \mathrm{min}$ per $50 \mathrm{~kg} \mathrm{LBM}$. 
Estimation of $C_{\mathrm{cr}}$ in $\mathrm{ml} / \mathrm{min}$ per $50 \mathrm{~kg} \mathrm{LBM}$

With stable serum creatinine levels (fluctuations below $0.5 \mathrm{mg} / 100 \mathrm{ml}$ ), $C_{\mathrm{cr}}$ can be estimated by:

$$
C_{\mathrm{cr}}=\frac{E}{S} \mathrm{ml} / \mathrm{min} \text { per } 50 \mathrm{~kg} \text { LBM (Hallynck et al., 1981). }
$$

Where $C_{\mathrm{cr}}=$ creatinine clearance in $\mathrm{ml} / \mathrm{min}$ per $50 \mathrm{~kg} \mathrm{LBM}, E=$ urinary creatinine excretion obtainable from Figure $1, S=$ measured serum creatinine in $\mathrm{mg} / 100 \mathrm{ml}$.

When the renal function is not stable and $S_{\mathrm{cr}}$ changes with at least $0.5 \mathrm{mg} / 100 \mathrm{ml}$, $C_{\mathrm{cr}}$ can be estimated by:

$$
C_{\mathrm{cr}}=\frac{E}{S}+600 . \frac{S_{1}-S_{2}}{T . S} \mathrm{ml} / \mathrm{min} \text { per } 50 \mathrm{~kg} \text { LBM (Hallynck et al., 1981). }
$$

$C_{\mathrm{cr}}=$ creatinine clearance in $\mathrm{ml} / \mathrm{min}$ per $50 \mathrm{~kg} \mathrm{LBM}$,

$E=$ urinary creatinine excretion obtainable from Figure 1,

$S_{1}=$ first serum creatinine concentration in $\mathrm{mg} / 100 \mathrm{ml}$,

$S_{2}=$ second serum creatinine concentration in $\mathrm{mg} / 100 \mathrm{ml}$,

$S=$ mean of $S_{1}$ and $S_{2}$.

$T=$ time interval between $S_{1}$ and $S_{2}$ in hours.

\section{Results}

A cure rate of $75 \%$ with a low incidence of toxicity $(2 \cdot 3 \%)$ was noted. Eighty-six of 124 serum amikacin peaks (70\%) lay between 20 and $30 \mathrm{mg} / \mathrm{l}$, and 112 (90\%) between 15 and $30 \mathrm{mg} / \mathrm{l}$. Only $3(2.4 \%)$ peaks were higher than $35 \mathrm{mg} / \mathrm{l}$. For trough levels, $105(83 \%)$ were found below $7 \mathrm{mg} / \mathrm{l}$ and $117(93 \%)$ out of 126 below $10 \mathrm{mg} / 1$ (Boelaert et al., 1980).

The amikacin half-life correlated significantly better $(P<0.02$ two-sided $t$-test) with the estimated $C_{\mathrm{cr}}$ in $\mathrm{ml} / \mathrm{min}$ per $50 \mathrm{~kg} \mathrm{LBM}(r=0.94)$ than with the measured 24-h endogenous $C_{\mathrm{cr}}(r=0 \cdot 77)$

No particular trend, decrease or increase of $\mathrm{C}_{\mathrm{cr}}$ compared with the original kidney function, was found. Over-all, in 27 patients the $C_{\mathrm{cr}}$ improved during therapy, with an average of $30 \%$ above the base-line level. In 16 patients, $C_{\mathrm{cr}}$ dropped, averaging $12 \%$ below the starting value. In two patients, $C_{\mathrm{cr}}$ improved significantly ( $>250 \%$ ) during therapy, and only in one patient, did $C_{\mathrm{cr}}$ drop to $58 \%$ of the original value. This patient was considered as developing possible nephrotoxicity.

In four patients mildly impaired hearing was reported during treatment. However, no difference was found between the follow-up period and the periods before and after treatment. In one patient, vestibular function became normal 1 month after the end of the therapy. 


\section{Discussion}

Prediction of drug half-life

When $C_{\mathrm{cr}}$ is normalized to the same distribution volume (e.g. $50 \mathrm{~kg} \mathrm{LBM}$ ), the following formulae are valid, independently of the age and the renal disease of the subject (Hallynck et al., 1981).

$$
\begin{aligned}
& K_{\mathrm{e}}=K_{\mathrm{nr}}+K_{\mathrm{r}}=K_{\mathrm{nr}}+\alpha \cdot C_{\mathrm{cr}}(\text { Dettli, 1977) } \\
& T / 2=\frac{0.693}{K_{\mathrm{e}}}=\frac{\frac{n .693}{\alpha}}{K_{\mathrm{nr}}+C_{\mathrm{cr}}}=\frac{F_{\mathrm{r}}}{F_{\mathrm{nr}}+C_{\mathrm{cr}}}
\end{aligned}
$$

$K_{\mathrm{e}}=$ total first-order elimination rate constant,

$K_{\mathrm{nr}}=$ non-renal first-order elimination constant,

$K_{\mathrm{r}}=$ renal first-order elimination constant,

$\alpha=$ proportionality constant relating the renal elimination rate constant of a drug and the creatinine clearance,

$C_{\mathrm{cr}}=$ creatinine clearance in $\mathrm{ml} / \mathrm{min}$ per $50 \mathrm{~kg} \mathrm{LBM}$,

$T 1 / 2$ = drug half-life,

$F_{\mathrm{r}}=$ renal correlation factor of drug elimination $C_{\mathrm{cr}}$,

$F_{\mathrm{nr}}=$ non-renal correlation factor of drug elimination and $\mathrm{C}_{\mathrm{cr}}$.

Creatinine clearance expressed as $\mathrm{ml} / \mathrm{min}$ per $50 \mathrm{~kg}$ lean body mass (LBM)

After McIntosh et al. (1928) recommended alurea clearance normalized to: $1 \cdot 73 \mathrm{~m}^{2}$ body surface area (BSA), the normalization of renal, hepatic or body clearance to BSA became a standard method.

However, to compare clearance values in different individuals it would be more logical to normalize the clearance to a standard distribution volume to be cleared.

Since the mean lean body mass (LBM) of a 25 -year-old adult is about $50 \mathrm{~kg}$, this value was chosen to calculate the standard distribution volume for hydrophilic compounds (drugs and body metabolites). Furthermore, in contrast with the BSA, the LBM is linearly related to the distribution volume of hydrophilic compounds (Hallynck et al., 1980).

When creatinine clearance values are correlated with drug half-lives, it is particularly important to normalize the clearance values to $50 \mathrm{~kg} \mathrm{LBM}$. Otherwise, quite different drug half-life values will be obtained in two individuals having different drug distribution volumes even though they may have the same creatinine clearance values. 


\section{Dosage guidelines}

With the guidelines presented, the actual amount of drug given is decreased and the dosing interval is prolonged. In this way, long periods of both unduly high serum concentrations and of sub-inhibitory concentrations will not occur. Within certain limits (see Appendix) the dosing interval can be freely chosen so that practicable times of drug administration can be selected. With a chosen dosing interval, the maintenance dose can be calculated exactly to provide reproducible serum peak levels after each drug administration. When the pocket dosing calculator is not available, the size of the maintenance dose can be taken as either three-quarters of the loading dose or the same as the loading dose, respectively, depending on whether the chosen dosing interval is nearer to 2 or to 3 times the drug half-life.

An important finding of this study was that therapeutic serum levels were obtained in patients with non-stable, as well as in those with stable, renal function. Furthermore, the low incidence of nephrotoxicity $(2 \cdot 3 \%)$ is notable in view of the fact that the majority of these patients had impaired renal function.

\section{Appendix}

\section{Practical applications for amikacin}

As a result of more than 5 years' experience with amikacin, we suggest the following dosage guidelines:

\section{(1) If the pocket dosing calculator is available}

Two different pocket calculators have been programmed for amikacin dosage guidelines. The calculators are commercially available (Hewlett-Packard HP-41C and Tandy TRS80) with an alpha-numeric display and a continuous memory up to 2 Kbytes. On the display, the calculator asks the user consecutively 'weight in $\mathbf{k g}$ (or lb)', 'height in $\mathrm{cm}$ (or inches)?', ... etc., and gives the specific dosage guidelines for the chosen patient, e.g. first dose $=1.9 \mathrm{ml}$; maintenance dose $=1.7 \mathrm{ml}$ every $24 \mathrm{~h}$.

In contrast to the manual method, the calculators correct for oedema, for decreases in the apparent intramuscular distribution volume in severely affected renal patients, and make a more accurate estimation of the maintanance dose:

$$
D_{\mathrm{m}}=D_{1} \cdot\left(1-\frac{1}{2^{\varepsilon}}\right)
$$

$D_{\mathrm{m}}=$ amount of drug in the maintenance dose,

$D_{1}=$ amount of drug in the loading dose,

$$
\varepsilon=\frac{\tau}{T / 2}=\text { relative dosing interval }(\varepsilon \text { is at least } 2)
$$

$\tau=$ chosen dose-interval in hours, $T / 2=$ drug half-life in hours. 
(2) If the pocket dosing calculator is NOT available

STEP 1: Estimate the LBM of the patient

$$
\begin{aligned}
& \text { for males: } \quad \mathrm{LBM}=1 \cdot 10 \mathrm{~W}-128 \frac{\mathrm{W}^{2}}{H^{2}} \text { (in } \mathrm{kg} \text { ) } \\
& \text { for females: } \mathrm{LBM}=1.07 \mathrm{~W}-148 \frac{\mathrm{W}^{2}}{H^{2}} \text { (in } \mathrm{kg} \text { ). }
\end{aligned}
$$

The mean LBM of an adult male is $80 \%$ and that of a female $75 \%$ of the total body weight.

STEP 2: Calculate the loading dose $\left(D_{1}\right)$

$D_{1}=\mathrm{LBM} \times 10$ (in mg).

STEP 3: Calculate the creatinine clearance $\left(C_{\mathrm{cr}}\right)$ using Figure 1

$$
C_{\mathrm{cr}}=\frac{E}{S}(\mathrm{ml} / \mathrm{min} \text { per } 50 \mathrm{~kg} \mathrm{LBM}) \text {. }
$$

STEP 4: Predict the drug half-life $T / 2$

$$
T / 2=\frac{171}{1+C_{\mathrm{cr}}}(\mathrm{h})
$$

STEP 5: Choose a practical dosing interval (at least and as closely as possible to $2 \times T / 2$ ) among every $12,24,36,48,72,96 \mathrm{~h}$ or any other intermediate practicable interval.

STEP 6: Calculate the maintenance dose $\left(D_{\mathrm{m}}=3 / 4 D_{1}\right.$, if the chosen interval is closer to $2 \times T / 2$ or $D_{\mathrm{m}}=D_{1}$ if the chosen interval is closer to $3 \times T / 2$

\section{Acknowledgement}

This research was supported by the Swiss National Science Foundation and by a grant from Bristol Meyers International Division, New York.

\section{References}

Behnke, A. R. \& Willmore J. H. (1975). Evaluation and Regulation of Body Build and Composition, pp. 155-173. Prentice-Hall Inc. Englewoods Cliffs, N.J.

Boelaert, J., Daneels, R., Fillastre, J. P., De Rosa, F., Rubinstein, E., Hatala M., Spousta, J., Soep, H. H., Hallynck, Th. \& Wenk, M. (1980). An altemative to blood level measurements in aminoglycosides. Abstracts of the Annual Meeting of the American Society for Microbiology $4, A-23$.

Dettli, L. (1977). Elimination kinetics and dosage adjustment of drug in patients with renal diseases. Progress in Pharmacology, Vol 1, nr 4. Fischer, Stuttgart-New York.

Dubois, D. \& Dubois, E. F. (1916). Clinical colorimetry. 10. A formula to estimate the approximate surface area if height and weight be known. Archives Internal Medicine 17, 863.

James, W. P. T. (1976). Research on Obesity. Her Majesty's Stationery Office, London. 
Hallynck. Th., Soep, H. H., Thomis, J. A., Boelaert, J., Daneels, R., Rubinstein, E., Reeves, D. S. \& Fillastre, J. P. (1980). Lean body mass and amikacin dosage. Journal of Antimicrobial Chemotherapy 6, 286-8.

Hallynck Th., Soep, H. H., Thomis, J. A., Boelaert, J., Daneels, R. \& Dettli, L. (1981). Should clearance be normalized to body surface or to lean body mass? British Journal of Clinical Pharmacology 11, 523-6.

Hallynck, Th., Soep, H. H., Thomis, J. A., Boelaert, J., Daneels, R., Fillastre, J. P., De Rosa F., Rubinstein, E., Hatala, M., Spousta, J. \& Dettli, L. (1981b). Prediction of creatinine clearance from serum creatinine concentration based upon lean body mass. Clinical Pharmacology and Therapeutics (in press).

McIntosh, J. F., Moller, E. \& Van Slycke D. D. (1928). Studies of urea excretion. III. The influence of body size on urea output. Journal of Clinical Investigation 6, 467-83.

Pijck, J. \& Hallynck, Th. (1981). Quality control in antibiotic assays. Proceedings of the Microbiological Meeting at St-Ode (Belgium). Elsevier, Amsterdam, The Netherlands (in press).

Reeves, D. S. \& Bywater, M. J. (1975). Quality control of serum gentamicin assaysexperience of national surveys. Journal of Antimicrobial Chemotherapy 1, 103-15. 